\title{
HISTOLOGY AND CYTOCHEMISTRY OF HUMAN SKIN
}

\author{
XI. The Distribution of $\beta$-Glucuronidase* \\ By William MonTagna, Ph.D. \\ (From the Arnold Biological Laboratory, Brown University, Providence, Rhode Island) \\ Plates 117 to 118 \\ (Received for publication, November 30, 1956) \\ INTRODUCTION \\ Beta-glucuronidase has been demonstrated histochemically in the skin of \\ the rat (8) and in that of man (2). This paper confirms the observations made \\ by other authors, and gives a more detailed account than is available on the \\ distribution of $\beta$-glucuronidase in the skin of man. All of the cutaneous ap- \\ pendages studied contain $\beta$-glucuronidase; the apocrine sweat glands and the \\ sebaceous glands contain the most. All of the cells in the dermis contain some \\ $\beta$-glucuronidase, but the mast cells seem to have a greater concentration than \\ the others.
}

\section{Materials and Methods}

Biopsy specimens of skin from the axilla, the back, and the scalp were fixed for 4 hours in neutral, unbuffered 10 per cent formalin. Frozen sections about $30 \mu$ in thickness were washed thoroughly in distilled water and then incubated in the buffered substrate mixture of Seligman, et $a l$. (8). In preparing the substrate mixture, $30 \mathrm{mg}$. of 6-bromo-2-naphthyl- $\beta$-D-glucuronide was dissolved in $5 \mathrm{cc}$. of absolute alcohol, to which was then added $20 \mathrm{cc}$. of phospho-citrate buffer $(\mathrm{pH} \mathrm{4.9)}$ and $75 \mathrm{cc}$. of distilled water. After enzyme hydrolysis of the ester for 8 hours at $37^{\circ} \mathrm{C}$., the product, 6 bromo-2-naphthol, was coupled with tetrazotized diorthoanisidine (diazo blue B), buffered to $\mathrm{pH} 7.5$ with phosphate buffer. Control sections exposed to hot steam and then incubated together with the others showed no enzyme activity. The sections were mounted in glycerin jelly. The azo dye at the place of enzyme reaction is soluble in fat, and preparations deteriorate after a few days if fats are present. The observations, therefore, were made soon after the tissues were prepared.

\section{OBSERVATIONS}

The cytoplasm of all the epidermal cells, from the basal layer to the stratum granulosum, stains a medium blue, an indication of moderate enzyme reaction (Figs. 1 and 2). The staining is never strong and does not occur in tissues that are incubated in the substrate for less than 8 hours. The cytoplasm of the cells of the stratum granulosum and the keratohyalin granules stain an

* This work was supported in part by a grant from the United States Public Health Service, RG 2125 C6. 
intense blue. These cells and those just above them form a strongly colored band which is easily distinguished from the rest of the epidermis (Fig. 2). A similar band has also been observed by others in the skin of the rat and of man $(2,8)$. The stratum corneum is almost unreactive.

At the junction of the epidermis and the ducts of the eccrine sweat glands, in the lower coil of the intraepidermal portion of the duct, there is an abrupt transition from the moderately reactive epidermis to the strongly reactive epithelium of the duct (Fig. 3). The reaction in the duct becomes increasingly intense and is strongest in the coiled, dermal portion (Fig. 4). Both layers of cells of the duct, and even the cuticle, are colored a deep blue. The basal cells are slightly more strongly reactive than the superficial cells.

A strong reaction of variable intensity is also always encountered in the secretory cells of the eccrine sweat glands. The lack of delicate resolution in these preparations does not permit one to discern precisely whether or not there is a difference in the distribution of the enzyme in the dark and light cells. The reaction, however, seems to be stronger in the light cells (Fig. 5). The cytoplasm and some coarse granules above the nucleus become colored a deep blue. The nuclei remain unstained. The myoepithelial cells have a very slight reaction.

The cells in the duct of apocrine glands are stained a moderately deep blue, like the cells of the outer root sheath of hair follicles. The secretory cells of the aprocrine glands, however, have the strongest concentration of enzyme reaction in the skin (Fig. 6). The base of each secretory cell is colored a homogeneous dark blue. The cytoplasm which bulges into the lumen is full of coarse, very strongly positive granules. In all cells, regardless of their sizes or shapes, the reaction is very strong all the way to the luminal edge. The myoepithelial cells are very lightly colored.

The wall of the pilary canal, in contrast with the surface epidermis, with which it is contiguous, is stained a moderately strong blue. The ducts of sebaceous glands are stained dark blue. The sebaceous glands are very strongly reactive (Fig. 8). The peripheral, undifferentiated cells are a homogeneous dark blue; the cells undergoing early differentiation and the mature sebaceous cells contain many intensely reactive granules of different sizes. The sebum shows no reaction.

The outer root sheath in the upper half of active hair follicles shows moderate enzyme reaction, particularly in the cells toward the periphery; the reaction diminishes centripetally. The inner border of the outer root sheath, and the inner root sheath, show no reaction. From about midway in the follicle to the bulb, the reaction in the outer root sheath becomes increasingly stronger. The cells of the outer root sheath around the level of the keratogenous zone of the cortex are full of very intensely staining granules. All of the cells of the lower part of the bulb, or matrix, are strongly reactive (Fig. 7). 
All of the layers of cells which move upward from the matrix also stain an intense, homogeneous blue color (Fig. 7). The layers of the inner root sheath and those of the cortex lose their reactivity when they begin to undergo keratinization. The cortex loses its reaction first, immediately above the constriction of the follicle, but the cells of the two layers of cuticle and the cells of Huxley's layer show some reaction up to about the middle of the follicle (Fig. 7). In Henle's layer the reaction fades at the constriction of the follicle. The dermal papilla of active hair follicles shows a very strong reaction in all of its cells.

In quiescent hair follicles enzyme reaction is concentrated in the entire outer root sheath, or epithelial sac. The reaction is not particularly strong, and resembles that in the pilary canal of active follicles. The cells of the dermal papilla are very small and show practically no reaction.

In the dermis, large amounts of $\beta$-glucuronidase are concentrated in the myelinated nerve fibers. Perhaps all nerve fibers contain some enzyme activity. The fibroblasts are usually unreactive, or they show at most a faint blue tint. The endothelial cells and the smooth muscle fibers of the arteries and of the arrectores pilorum are moderately reactive. The cells of the blood vessels around active hair follicles and sebaceous glands and those in the papillary layer show some enzyme activity. The recognizable mature mast cells in the papillary layer contain intensely reactive coarse granules; those in the adipose layer and those in the areolar tissue around sweat glands are intensely stained (Fig. 9).

The young fat cells in the adipose layer contain dark blue staining granules in the cytoplasm. Similar granules are also found in the cytoplasm in the periphery of mature fat cells (8). The fibroblasts in the fatty layer are more strongly reactive than those elsewhere.

\section{DISCUSSION}

It has been demonstrated previously that human skin contains a great deal of $\beta$-glucuronidase (3). When the dermis and epidermis were separated, the epidermis yielded considerably more enzyme activity than the dermis. Histochemical studies, however, only partially support this observation, and the cutaneous appendages found in the dermis are much richer in $\beta$-glucuronidase than is the epidermis. An explanation for this may be that the specimens of human skin used for biochemical analysis were from the female breast, an area of skin that contains relatively few appendages. If skin containing numerous sweat glands, hair follicles, and sebaceous glands had been used, the figures would have been different.

The histochemical findings in this investigation are in agreement with those of Braun-Falco (2). The secretory coil of both eccrine and apocrine sweat glands has heavy concentrations of $\beta$-glucuronidase, but the enzyme is much 
more abundant in the apocrine glands. In this respect, the distribution of $\beta$-glucuronidase in sweat glands is like that of short-chain esterases (1). No other structure in the skin contains so much $\beta$-glucuronidase as the apocrine glands.

The distribution of the enzyme in hair follicles is similar to that of succinic dehydrogenase (7). The strongest concentration of $\beta$-glucuronidase is in the outer root sheath around the level of the keratogenous zone. The cells in this level of the root sheath are laden with glycogen and with substances which stain metachromatically $(5,6)$. The keratogenous zone of the cortex is a region of high protein synthesis, and requires ready access to sources of energy. Being removed from the blood supply, its closest path of exchange is by way of the outer root sheath. The outer root sheath, at this level, must be a very active metabolic entity, and through it a great deal of exchange must take place. The dermal papilla, another site of high metabolic, and possibly also inductive activity, also has strong concentrations of $\beta$-glucuronidase. In quiescent follicles the reaction for $\beta$-glucuronidase is much reduced in the outer root sheath, and there is practically no reaction in the dermal papilla.

In active hair follicles, $\beta$-glucuronidase is most concentrated in the same places where there are substances which stain metachromatically with toluidine blue, and which are probably mucopolysaccharides. The dermal papilla and the outer root sheath of quiescent hair follicles do not contain metachromatically staining substances, and they also show a dramatic reduction in $\beta$-glucuronidase.

$\beta$-glucuronidase is abundant as well in adipose tissues, sebaceous glands, and in myelinated nerve fibers but there is no intention to infer from this that $\beta$-glucuronidase should be equated with lipide synthesis. In the epidermis a band with strong enzyme activity corresponds to a band also rich in esterase $(4,1)$. This band of the epidermis seems to be associated with lipide synthesis or liberation.

The presence of $\beta$-glucuronidase in mast cells may prove to be significant if these cells really secrete glucuronides. The mast cells of the mouse, the rat, and the cat also contain the enzyme, and this is a characteristic feature of these cells.

SUMMARY

1. Various amounts of $\beta$-glucuronidase activity may be found in all of the cutaneous appendages.

2. In the epidermis, the basal layer and the Malpighian layer contain a moderate amount of it, but a band of cells, including the stratum granulosum and the cells immediately above it, is rich in $\beta$-glucuronidase.

3 . The cells of the duct of eccrine sweat glands have moderately strong enzyme activity, but those in the secretory coil are strongly reactive; small and large reactive granules are crowded in the reactive cytoplasm. 
4 . The cells of the secretory coil of the apocrine glands contain more $\beta$-glucuronidase than any other cutaneous appendage.

5. In the sebaceous glands, a very strong concentration of enzyme activity is found in the undifferentiated peripheral cells, a smaller amount of it is found in the differentiating cells.

6. In active hair follicles, the largest amount of $\beta$-glucuronidase is found in the outer root sheath and in the bulb. In the outer sheath, the strongest concentration is found around the level of the keratogenous zone of the cortex. The dermal papilla is strongly reactive. In quiescent hair follicles, the outer root sheath has a moderate amount of enzyme concentration, but the dermal papilla is unreactive.

7. In the dermis, the fibroblasts in the papillary layer, the smooth muscle cells of the arrectores pilorum and the tunica media of arteries, and the fat cells all exhibit enzyme activity. Mast cells show a great concentration of $\beta$-glucuronidase.

\section{BIBLIOGRAPHY}

1. Braun-Falco, O., Arch. klin. u. exp. Dermatol., 1956, 202, 153.

2. Braun-Falco, O., Arch. klin. u. exp. Dermatol., 1956, 203, 61.

3. Mesirow, S. M., and Stoughton, R. B., J. Inv. Dermatol., 1954, 23, 315.

4. Montagna, W., J. Biophysic. and Biochem. Cytol., 1955, 1, 13.

5. Montagna, W., Chase, H. B., and Lobitz, W. C., Jr., Anat. Rec., 1952, 114, 231.

6. Montagna, W., Chase, H. B., and Melaragno, H. P., J. Nat. Cancer Inst., 1951, 12, 591 .

7. Montagna, W., and Formisano, V., Anat. Rec., 1955, 122, 65.

8. Seligman, A. M., Tsou, K. C., Rutenburg, S. H., and Cohen, R. B., J. Histochem. and Cytochem., 1954, 2, 209. 


\section{EXPLANATION OF PLATES}

\section{Piate 117}

Fig. 1. The epidermis from the back, with a moderate amount of enzyme activity in the Malpighian layer. The stratum granulosum and the cells just above it form a strongly reactive band. This is seen better in Fig. $2 . \times 75$.

FIG. 2. Enlarged detail of Fig. 1. The band rich in $\beta$-glucuronidase is clearly visible. $\times 250$.

FIG. 3. Enzyme activity in the intraepidermal portion of the duct of an eccrine sweat gland. Contrast the strength of the reaction in the duct, in the lower part of the figure, with that of the epidermis, in the upper part of the figure. $\times 65$.

Fig. 4. Segments of a coiled part of an eccrine sweat gland. The arrow points to a secretory segment. Both duct and secretory segment are strongly reactive. $\times 65$.

Fig. 5. Transverse section through the secretory coil of an eccrine sweat gland. The clear cells seem to have a stronger concentration of the enzyme than the dark cells. $\times 750$. 
THE JOURNAL OF

BIOPHYSICAL AND BIOCHEMICAL

PLATE 117 CYTOLOGY

VOL. 3
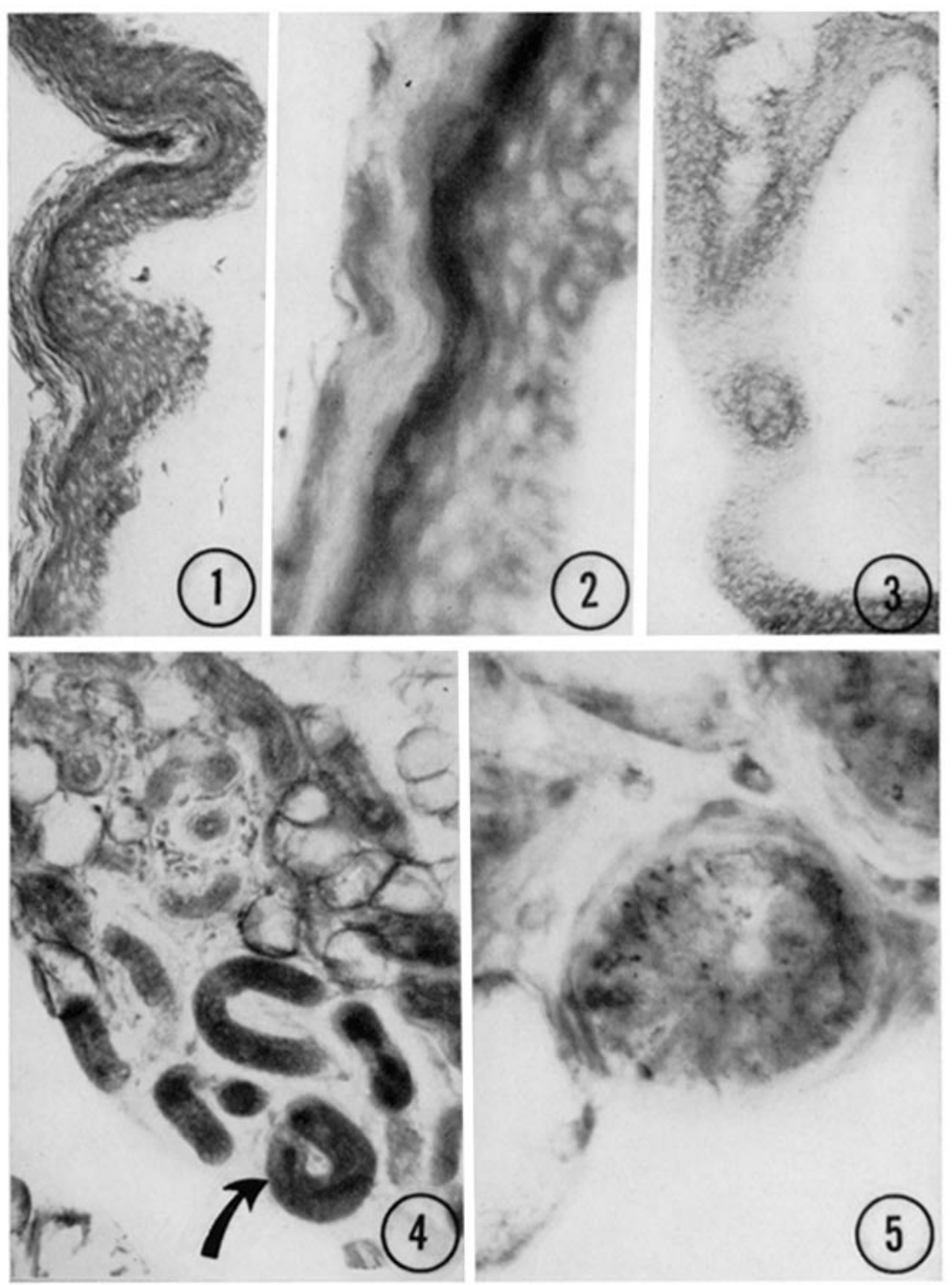

(Montagna: $\beta$-Glucuronidase in human skin) 


\section{Plate 118}

Fig. 6. Intense reaction in the secretory cells of an apocrine sweat gland from the axilla. The luminal border is on the right of the figure. $\times 250$.

Fig. 7. Beta-glucuronidase reaction in an active hair follicle from the axilla. The arrow points to the lower level of the keratogenous zone. The black center of the bulb is melanin and does not indicate enzyme activity. The reaction is very strong in the cells of the cuticle of the cortex and of the inner root sheath. $\times 75$.

Fig. 8. Very strong enzyme reaction in sebaceous glands. $\times 75$.

FIg. 9. Strong, granular reaction in the mast cells (arrows). This is an enlarged detail of Fig. 4 , in which mast cells are very numerous. $\times 750$. 
THE JOURNAL OF

BIOPHYSICAL AND BIOCHEMICAI

CYTOLOGY
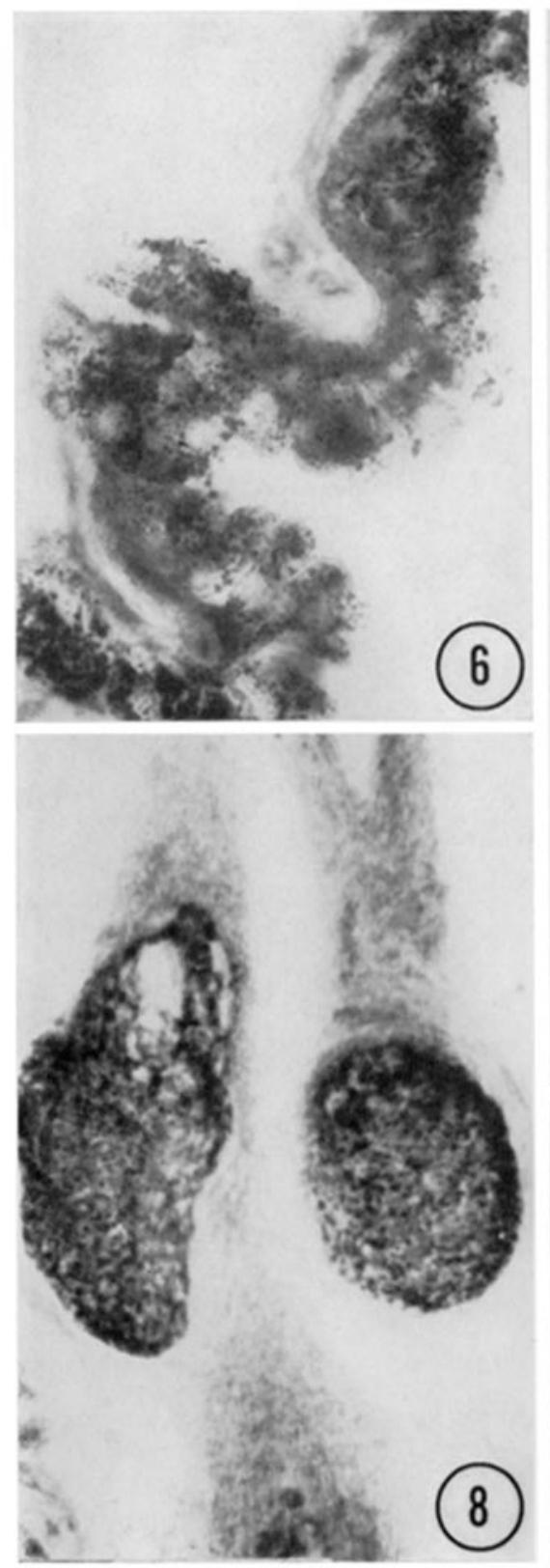

(8)
PLATE 118

VOL. 3
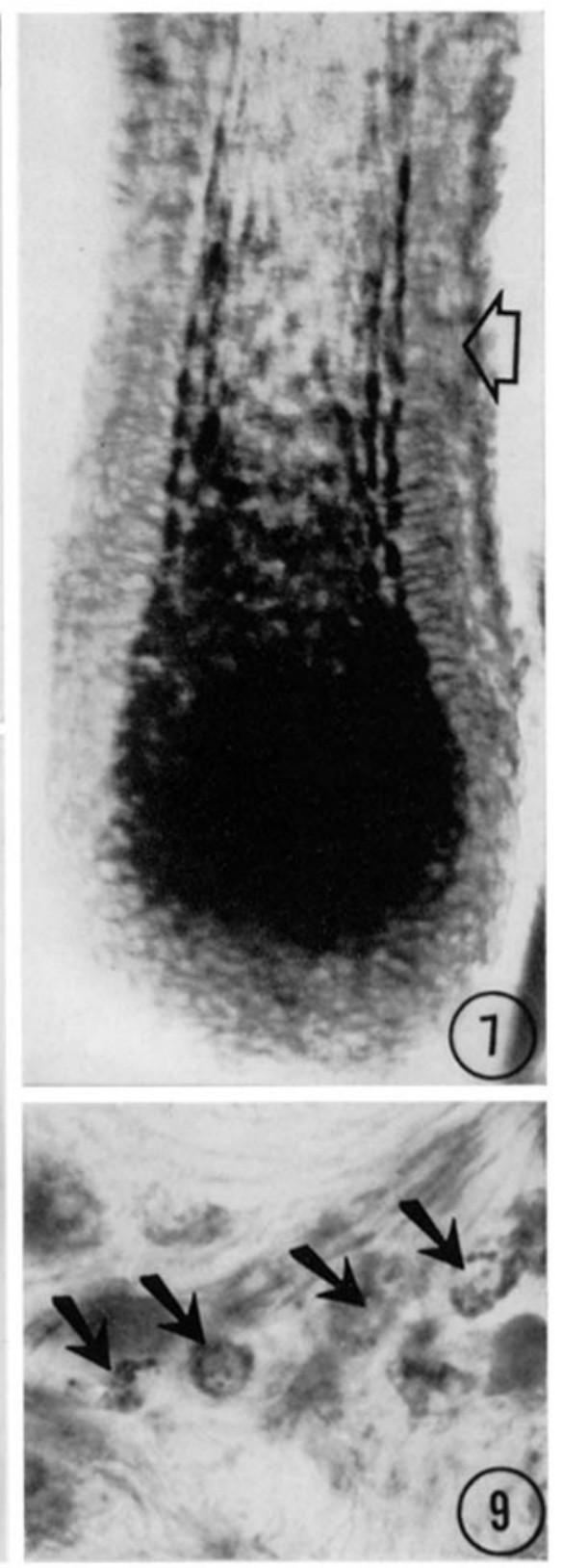

(Montagna: $\beta$-Glucuronidase in human skin) 